\title{
EDITORIAL
}

\section{Advances in Oncolytic Antitumour Adenoviral Therapies: Three Key Aspects}

Programa Gens i Malaltia. Centre de Regulació Genòmica-CRG, UPF, Parc de Recerca Biomèdica de Barcelona-PRBB and Centro de Investigación Biomédica en Red de Enfermedades Raras (CIBERER), Barcelona Spain.

Oncolytic virotherapy based on adenoviral vectors is an intensive area of research and many advances are being conducted with the general aim to come up with full potential oncolytic adenoviruses to be effective in the human clinical context. Two main concepts are driving the genetic engineering of adenoviruses. On one hand there are the strategies directed towards enhancing the viral potency and on the other those that focus on adenoviral selectivity.

This special issue reviews current research on adenoviral oncolysis by focusing on three key aspects in adenoviral biology: viral entrance to the cell, viral replication, and viral exit from the cell. The first review "Targeting adenoviral entry to enhance oncolytic antitumor response" discusses on the effectiveness of pseudotyping, genetic targeting or the use of adaptor molecules to enter adenovirus into tumor cells. It also summarizes the effects of detargeting adenovirus from their natural tropism, of special interest in systemic applications to treat disseminated disease.

The second review "Controlling adenoviral replication to induce oncolytic efficacy" discusses on the broad number of genetic elements that are being engineer into the adenoviral genome to control replication. And how the increased knowledge on the specific behavior and regulation of neoplastic cells and tumor microenvironment can be exploited to develop novel oncolytic adenoviruses.

The third review "Adenovirus release from the infected cell as a key factor for adenoviral oncolysis" summarizes the strategies used to facilitate adenoviral spreading into the tumor by favoring the release from the infected cells. In a first term it reviews the biology of adenoviral release.

This special issue highlights the hot-topic aspects in the expanding field of adenoviral oncolysis where many new and exciting developments are rapidly being generated.

(C) Cristina Fillat; Licensee Bentham Open.

This is an open access article licensed under the terms of the Creative Commons Attribution Non-Commercial License (http://creativecommons.org/licenses/by-nc/3.0/) which permits unrestricted, non-commercial use, distribution and reproduction in any medium, provided the work is properly cited.

Cristina Fillat

(Guest Editor)

Centre de Regulació Genòmica, Dr. Aiguader, 88. 08003-Barcelona

Tel: +34-933160142

E-mail: cristina.fillat@crg.es 